Article

\title{
Resveratrol-Induced Changes in MicroRNA Expression in Primary Human Fibroblasts Harboring Carnitine-Palmitoyl Transferase-2 Gene Mutation, Leading to Fatty Acid Oxidation Deficiency
}

\author{
Virginie Aires ${ }^{1,2}$, Dominique Delmas ${ }^{1,2}$, Fatima Djouadi ${ }^{3}$, Jean Bastin ${ }^{3}$, \\ Mustapha Cherkaoui-Malki ${ }^{1}$ and Norbert Latruffe ${ }^{1, *}$ \\ 1 Laboratory BioPeroxIL, University of Bourgogne-Franche Comté, 6 Blvd Gabriel, 21000 Dijon, France; \\ virginie.aires02@u-bourgogne.fr (V.A.); ddelmas@u-bourgogne.fr (D.D.); malki@u-bourgogne.fr (M.C.-M.) \\ 2 INSERM UMR 866, Blvd Jeanne d'Arc, 21490 Dijon, France \\ 3 INSERM U1124, Université Paris-Descartes, Rue des Saints-Pères, 75000 Paris, France; \\ Fatima.djouadi@inserm.fr (F.D.); jean.bastin@inserm.fr (J.B.) \\ * Correspondence: latruffe@u-bourgogne.fr; Tel.: +33-380-396-237
}

Received: 13 November 2017; Accepted: 16 December 2017; Published: 22 December 2017

\begin{abstract}
Carnitine palmitoyltransferase-2 (CPT2) is a mitochondrial enzyme involved in long-chain fatty acid entry into mitochondria for their $\beta$-oxidation and energy production. Two phenotypes are associated with the extremely reduced $C P T 2$ activity in genetically deficient patients: neonatal lethality or, in milder forms, myopathy. Resveratrol (RSV) is a phytophenol produced by grape plant in response to biotic or abiotic stresses that displays anti-oxidant properties, in particular through AP-1, NFkB, STAT-3, and COX pathways. Some beneficiary effects of RSV are due to its modulation of microRNA (miRNA) expression. RSV can enhance residual CPT2 activities in human fibroblasts derived from CPT2-deficient patients and restores normal fatty acid oxidation rates likely through stimulation of mitochondrial biogenesis. Here, we report changes in miRNA expression linked to CPT2-deficiency, and we identify miRNAs whose expression changed following RSV treatment of control or CPT2-deficient fibroblasts isolated from patients. Our findings suggest that RSV consumption might exert beneficiary effects in patients with CPT2-deficiency.
\end{abstract}

Keywords: resveratrol; miRNA level; $C P T 2$-deficient cells

\section{Introduction}

Resveratrol (RSV, trans-3,5, $4^{\prime}$-trihydroxystilbene) is a phytoalexin produced by numerous plants in response to abiotic or biotic stress [1-3]. This polyphenol compound admittedly protects humans against various diseases (cardiovascular and inflammation-associated pathologies, infection, cancer, neurodegenerescence, aging, etc.) through the modulation of several signaling pathways, including those mediated by transcription factors AP-1 [4], NFKB, and STAT-3 [5] or the COX enzyme [6]. RSV has been shown to improve residual $\beta$-oxidation in primary human fibroblasts from CTP2-deficient patients by restoring normal fatty acid oxidation rates [7].

MicroRNAs are short, non-coding regulatory microRNAs present in plants, animals, and viruses. To date, more than 1500 miRNAs have been identified in humans. MiRNA primarily controls mRNA translation and stability. Due to their ability to regulate several hundred transcripts directly or indirectly through targeting components of key regulatory pathways, miRNAs behave as master regulators that impact all aspects of cell homeostasis and functions. Many miRNAs are considered either as tumor suppressor or onco-miRs, depending on the cellular context [8]. 
There is now a substantial amount of literature on miRNAs, including a few studies that have addressed the differential effects of polyphenols on miRNA expression [8-13]. In 2010, we demonstrated the regulatory effect of RSV on the expression of miRNAs involved in macrophage-associated inflammatory response [8] as well as on the expression of components of the TGF $\beta$ regulatory pathway in colon cancer cell lines [14]. Interestingly, in 2013, Milenkovic et al. [10] established that the expression of more than 100 miRNAs is modulated by polyphenols. These authors reported that various different polyphenols have both common and specific miRNA targets. Indeed, in mouse livers, over 137 miRNAs are modulated by phytophenols of the stilbenoids family (including resveratrol). While stilbenoids modulated the expression of 87 of these 137 miRNAs, 24 other miRNAs were targets of flavonoids, 6 of phenolic acids, and 20 of curcuminoids. This analysis further confirms that the different classes of polyphenols not only share common properties (as anti-oxidant for instance) but also have their own specific effects due to their unique chemical structure and reactivity and their differential effects on gene expression, especially miRNAs.

Presently, more than a hundred papers have confirmed that the effect of RSV in the prevention or treatment of various diseases, including prostate cancer [15], melanoma [16], breast cancer [17], lung tumors [18], white adipogenesis [19], liver steatosis [20], inflammation [21,22], neurodegenerative disorders [23], and osteoporosis [24], were mediated by miRNAs.

In the present study, we report the RSV-induced modulation of energy metabolism miRNA in human cells harboring mitochondrial fatty acid B-oxidation-deficiency as a result of carnitine-palmitoyl transferase $2(C P T 2)$ gene mutations. CPT2 is a mitochondrial inner membrane enzyme playing an essential role in the transfer of fatty acids from the cytosol to the mitochondrial matrix. In 2011, Bastin et al. [7] showed that RSV is able to enhance residual CPT2 activity in human fibroblasts derived from patients harboring the muscular form of CTP2 deficiency and can restore near-normal fatty acids oxidation rates, opening potential clinical perspectives to successfully treat the CPT2-deficiency-associated myopathy. This stimulation was also observed with other analogues of the stilbene family [25]. In this study, we compared miRNA expression in control and CPT2-deficient primary human fibroblasts and analyzed RSV's impact on miRNA expression in both cell lines.

\section{Results and Discussion}

\subsection{Changes in miRNA Expression Associated with Mitochondrial CPT2-Deficiency in Primary Human Fibroblasts}

Table 1 shows that CPT2-deficiency was associated with significant changes in the levels of 51 miRNA in patient fibroblasts. More specifically, CPT2-deficient fibroblasts showed 13 upregulated miRNAs (with an 11-fold increase for miR-301 in particular) and 38 downregulated miRNAs, including 3 miRNAs from the miR-let-7 family. The multiplicity of miRNA target transcripts suggests that the fibroblast transcriptome might be widely affected by $C P T 2$-deficiency.

Table 1. MiRNAs whose expression changed in human CPT2-deficient primary fibroblasts as compared with control primary human fibroblasts, as deduced from microRNA microarray analysis. Geometric mean of intensities $<100$ were considered as background and discarded. Changes were considered significant for $p<0.05$.

\begin{tabular}{ccc}
\hline miRNAs & Fold Change & Increasing Parametric $\boldsymbol{p}$ Value \\
\hline & miRNAs upregulated in CPT2-deficient fibroblasts: \\
\hline 483 & 3.1 & $1.6 \times 10^{-6}$ \\
301 & 11.43 & $4.1 \times 10^{-6}$ \\
$449 \mathrm{~b}$ & 1.99 & $2.79 \times 10^{-6}$ \\
206 & 3.38 & $9.39 \times 10^{-6}$ \\
$550-1$ & 2.83 & 0.000171 \\
539 & 2.04 & 0.0002213 \\
661 & 2.79 & 0.0004408 \\
371 & 2.65 & 0.0005968 \\
\hline
\end{tabular}


Table 1. Cont.

\begin{tabular}{|c|c|c|}
\hline miRNAs & Fold Change & Increasing Parametric $p$ Value \\
\hline \multicolumn{3}{|c|}{ miRNAs upregulated in CPT2-deficient fibroblasts: } \\
\hline $10 \mathrm{~b}$ & 2.75 & 0.0011091 \\
\hline 9 & 4.4 & 0.0014253 \\
\hline $550-2$ & 2.1 & 0.0016581 \\
\hline 651 & 2.87 & 0.0019172 \\
\hline $196 a-2$ & 2.09 & 0.0019172 \\
\hline \multicolumn{3}{|c|}{ miRNAs downregulated in CPT2-deficient fibroblasts: } \\
\hline let-7d & 0.16 & $<1 \times 10^{-7}$ \\
\hline 211 & 0.14 & $4 \times-10^{-7}$ \\
\hline let-7a3 & 0.22 & $1.2 \times 10^{-6}$ \\
\hline 198 & 0.14 & $2.8 \times 10^{-6}$ \\
\hline 141 & 0.28 & $4.6 \times 10^{-6}$ \\
\hline 136 & 0.31 & $5.1 \times 10^{-6}$ \\
\hline 203 & 0.24 & $5.7 \times 10^{-6}$ \\
\hline 127 & 0.23 & $7.7 \times 10^{-6}$ \\
\hline $181 \mathrm{c}$ & 0.26 & $1.85 \times 10^{-5}$ \\
\hline 496 & 0.3 & $2.5 \times 10^{-5}$ \\
\hline $126-5 p$ & 0.14 & $3.64 \times 10^{-5}$ \\
\hline 144 & 0.097 & $3.8 \times 10^{-5}$ \\
\hline let-7g & 0.48 & $4.14 \times 10^{-5}$ \\
\hline $181 \mathrm{a} 2$ & 0.44 & $4.42 \times 10^{-5}$ \\
\hline 618 & 0.48 & $4.47 \times 10^{-5}$ \\
\hline 41 & 0.15 & $4.5 \times 10^{-5}$ \\
\hline $299-5 p$ & 0.14 & $4.73 \times 10^{-5}$ \\
\hline 1 & 0.41 & $4.88 \times-10^{-5}$ \\
\hline 145 & 0.32 & $4.94 \times 10^{-5}$ \\
\hline 25 & 0.26 & $6.37 \times 10^{-5}$ \\
\hline 123 & 0.31 & $6.67 \times 10^{-5}$ \\
\hline $200 \mathrm{~b}$ & 0.27 & $8.33 \times 10^{-5}$ \\
\hline 325 & 0.44 & $8.51 \times 10^{-5}$ \\
\hline 593 & 0.42 & $9.19 \times 10^{-5}$ \\
\hline $24-5 p / 189$ & 0.14 & 0.0001524 \\
\hline $125 \mathrm{~b} 2$ & 0.1 & 0.0002071 \\
\hline 123 & 0.25 & 0.0002196 \\
\hline $154-5 p$ & 0.3 & 0.0002281 \\
\hline 184 & 0.43 & 0.0002499 \\
\hline $199 b$ & 0.47 & 0.0005099 \\
\hline 22 & 0.25 & 0.0006033 \\
\hline $363-3 p$ & 0.37 & 0.0006076 \\
\hline 338 & 0.24 & 0.0007282 \\
\hline $146 a$ & 0.42 & 0.0008154 \\
\hline 212 & 0.28 & 0.0008813 \\
\hline $196 a-1$ & 0.34 & 0.0008916 \\
\hline 500 & 0.29 & 0.0013401 \\
\hline 563 & 0.47 & 0.0016458 \\
\hline
\end{tabular}

\subsection{RSV-Induced Changes in miRNA Expression in Control and CPT2-Deficient Primary Human Fibroblasts}

Table 2 shows changes in miRNA expression induced by RSV treatment in both control and CPT2-deficient fibroblasts. Twelve miRNAs were upregulated and 24 miRNAs downregulated in control fibroblasts, versus 8 miRNAs upregulated and 16 miRNAs downregulated in CPT2-deficient fibroblasts. Of note, $m i R-566$ and $m i R-23 a, b$ were downregulated in both control and patient fibroblasts following RSV treatment, suggesting that these changes might result from RSV specific action on factors controlling transcription and/or maturation of these two miRNAs, irrespective of cell genotype 
or of energy metabolism deficiency. On the other hand, miR-550-1,2 was upregulated and miR-let7-a3 was downregulated in both untreated CPT2-deficient fibroblasts (Table 1) and RSV-treated control fibroblasts (Table 2). If one considers that RSV exerts beneficial effects on the cell, this suggests that the changes in expression of these two miRNAs might be advantageous in both cases. Finally, the expression of other miRNAs changed in both untreated and RSV-treated CPT2-deficient fibroblast. Thus, miR-181a2,d, miR-let7d, and miR-146a were downregulated in both untreated and RSV-treated CPT2-deficient fibroblast (Tables 1 and 2). This suggests that the upregulation of these three miRNAs might provide $C P T 2$-deficient fibroblasts with an increased ability to survive with reduced catabolism of long chain fatty acids. 
Table 2. RSV $(75 \mu \mathrm{M})$ treatment impacts miRNA expression in control and in CPT2-deficient fibroblasts, compared with the corresponding DMSO-treated primary fibroblasts, as deduced from microRNA microarray analysis. Geometric mean of intensities $<100$ were considered as background and discarded. Changes were considered significant when $p<0.05$.

\begin{tabular}{|c|c|c|c|c|c|c|c|c|c|c|c|}
\hline \multicolumn{6}{|c|}{ Control Fibroblasts } & \multicolumn{6}{|c|}{ CPT2-Deficient Fibroblasts } \\
\hline \multicolumn{3}{|c|}{ Upregulation by RSV } & \multicolumn{3}{|c|}{ Downregulation by RSV } & \multicolumn{3}{|c|}{ Upregulation by RSV } & \multicolumn{3}{|c|}{ Downregulation by RSV } \\
\hline miRNA & Fold Change & $\begin{array}{c}\text { Increasing } \\
\text { Parametric } p \text { Value }\end{array}$ & miRNA & Fold Change & $\begin{array}{c}\text { Increasing } \\
\text { Parametric } p \text { Value }\end{array}$ & miRNA & Fold Change & $\begin{array}{c}\text { Increasing } \\
\text { Parametric } p \text { Value }\end{array}$ & miRNA & Fold Change & $\begin{array}{c}\text { Increasing } \\
\text { Parametric } p \text { Value }\end{array}$ \\
\hline 321 & 3.67 & 0.0003277 & 35 & 0.47 & 0.0011099 & 219 & 1.81 & 0.00028111 & $101-1 / 2$ & 0.51 & 0.000758 \\
\hline 594 & 3.33 & 0.000695 & $548 \mathrm{a}-1$ & 0.28 & 0.0011964 & $299-5 p$ & 1.94 & 0.00037058 & 181d & 0.45 & 0.00021178 \\
\hline $550-2$ & 2.65 & 0.0026216 & 566 & 0.49 & 0.0014556 & $193 a$ & 1.96 & 0.00074255 & $16-1$ & 0.48 & 0.00022522 \\
\hline 565 & 2.87 & 0.0066109 & 620 & 0.49 & 0.0031365 & $199 a 1-5 p$ & 1.8 & 0.035782 & 21 & 0.47 & 0.00023066 \\
\hline 611 & 2.18 & 0.0100121 & $92 \mathrm{~b}$ & 0.24 & 0.003498 & $548 \mathrm{a} 1$ & 2.3 & 0.041391 & $99 \mathrm{a}^{*}$ & 0.27 & 0.00041291 \\
\hline 483 & 2.29 & 0.0118661 & $378-5 p$ & 0.41 & 0.0070053 & 337 & 1.89 & 0.0488272 & $20 \mathrm{~b}$ & 0.47 & 0.00053956 \\
\hline 335 & 2.69 & 0.0158687 & 579 & 0.19 & 0.020456 & & & & let-7d & 0.46 & 0.00071834 \\
\hline $550-1$ & 2.35 & 0.0182839 & 136 & 0.46 & 0.0206073 & & & & $17-5 \mathrm{p}$ & 0.43 & 0.0007255 \\
\hline $449 \mathrm{~b}-1$ & 1.99 & 0.021485 & let-7f & 0.44 & 0.0220297 & & & & $146 a$ & 0.27 & 0.0110431 \\
\hline 661 & 2.45 & 0.0256413 & 211 & 0.24 & 0.0220881 & & & & 566 & 0.5 & 0.012436 \\
\hline 326 & 3.58 & 0.0315627 & $376 a-2$ & 0.42 & 0.024334 & & & & $376 \mathrm{~b}$ & 0.47 & 0.012361 \\
\hline \multirow[t]{13}{*}{ 196a-1 } & 3.45 & 0.0369082 & $193 a$ & 0.23 & 0.0255173 & & & & $26 a$ & 0.46 & 0.0130816 \\
\hline & & & $29 a$ & 0.47 & 0.0265262 & & & & $103-1$ & 0.35 & 0.0166397 \\
\hline & & & $199 \mathrm{~b}$ & 0.44 & 0.0294717 & & & & let-7c & 0.28 & 0.0192349 \\
\hline & & & 141 & 0.26 & 0.029536 & & & & 423 & 0.14 & 0.0231317 \\
\hline & & & 204 & 0.33 & 0.0295895 & & & & $23 a$ & 0.18 & 0.0257826 \\
\hline & & & 216 & 0.3 & 0.0311748 & & & & & & \\
\hline & & & let-7a3 & 0.29 & 0.0323893 & & & & & & \\
\hline & & & 618 & 0.44 & 0.0361713 & & & & & & \\
\hline & & & 198 & 0.43 & 0.0375283 & & & & & & \\
\hline & & & 22 & 0.39 & 0.0379847 & & & & & & \\
\hline & & & $126-5 p$ & 0.26 & 0.0463448 & & & & & & \\
\hline & & & $23 \mathrm{~b}$ & 0.49 & 0.0469568 & & & & & & \\
\hline & & & 144 & 0.26 & 0.0496528 & & & & & & \\
\hline
\end{tabular}


2.3. Mirna Whose Expression Changed in CPT2-Deficient Primary Fibroblasts, Regardless of RSV Treatment, Target Pathways Involved in Fatty Acid Oxidation

We have shown in previous studies that treatment by resveratrol similar to that used in the present study induced a dose-dependent increase in fatty acid oxidation in CPT2-deficient patients [25]. Furthermore, this dose of resveratrol was shown to correct not only CPT2 deficiency, but also other fatty acid oxidation and respiratory chain deficiencies $[7,26,27]$. In all these experiments, the human fibroblasts did not exhibit growth changes or increased mortality. It was thus essential to use the same treatment conditions in order to investigate the changes in microRNA expression in response to resveratrol. We also showed previously that treating mouse RAW264.7 macrophages with a 10 to $100 \mu \mathrm{M}$ range of resveratrol concentrations decreased JunB expression as well as AP-1 activity in a dose-dependent manner (Supplementary figure 3 in the manuscript of Tili et al. [4]). Thus, we believe that treatment by $75 \mu \mathrm{M}$ resveratrol, despite representing a high concentration, should not have caused any bias in our microarrays analyses.

The marked beneficial effects of treatment on fatty acid oxidation in the patient fibroblasts could suggest that resveratrol directly regulates CPT2 expression. However, the precise signaling pathway(s) by which RSV targets fatty acid oxidation in the context of CPT2-deficiency is still a matter of debate. Several polyphenols, including RSV have been shown to increase the activity and gene expression of SIRT1 accompanied by the increase in CPT1 mRNA encoding the rate-limiting enzyme of mitochondrial fatty acid oxidation [28]. SIRT1-dependent de-acetylation of PGC-1 $\alpha$ leads to the transcriptional co-activation of nuclear and mitochondrial genes encoding for proteins promoting mitochondrial biogenesis, oxidative phosphorylation and energy production. On the other hand, SIRT3 mediates direct activation of proteins implicated in oxidative phosphorylation, tricarboxylic acid (TCA) cycle and fatty-acid oxidation, in addition to an indirect activation of PGC- $1 \alpha$ and AMP-activated protein kinase (AMPK). SIRT1 is required for the activation of AMPK, which enhances energy-production through glucose transport, fatty acid oxidation, or mitochondrial biogenesis [29,30]. The action of resveratrol to correct CPT2-deficiency might therefore involve SIRT1, however, definite evidence based on silencing SIRT1 expression in patient fibroblasts is lacking. Altogether, there is a general consensus in the literature supporting RSV effects being mediated through an AMPK/SIRT1/PGC-1 $\alpha$ pathway [31]. It has also been suggested that RSV effects might also occur through the estrogen receptor (ER), which RSV can bind and activate [23]. We therefore examined whether the $3^{\prime}$-untranslated regions of genes implicated in the two above pathways contain consensus target sites for those miRNAs whose expression changed either in untreated CPT2-deficient fibroblasts as compared with control fibroblasts (Table 1) or in CPT2-deficient fibroblasts treated with RSV as compared with DMSO-treated CPT2-deficient fibroblasts (Table 2).

The general mechanism associated with microRNA action involves the reduced expression of their target genes. Using the Targetscan software (www.targetscan.com), we found consensus target sequences for miRNAs that were upregulated, as well as for miRNAs that were downregulated, in untreated CPT2-deficient fibroblasts (Table 3). In particular, miR-483, the miRNA that increased with the lowest $P$ value in Table 1 , targeted seven genes of the above pathways. It was followed by $m i R-449 b$, $m i R-371$ (with often multiple target sequences in the same transcripts), and miR-9 (6 genes targeted) and then by miR-539 and miR-301 (5 and 4 genes targeted, respectively). In contrast, except for miR-181a2,c (seven genes targeted), the miRNAs downregulated in untreated CPT2-deficient fibroblasts did not target more than 4 genes (miR-211 and miR-126a-5) (Table 3), and, except miR-211, were not among the miRNAs that changed with the lowest $P$ value in Table 1 . Although it would be almost impossible to measure the relative effects of these miRNAs on the expression of each of these putative target genes, the above observation suggests that the effects of upregulated miRNAs as a whole might be greater than those of downregulated miRNAs, leading to reduced levels of expression of their respective target gene and, as a consequence, reduced fatty acid oxidation. 
Table 3. Putative targets transcripts of miRNAs of Tables 1 and 2.

\begin{tabular}{|c|c|c|}
\hline Genes & Proteins & MiRNAs * \\
\hline \multicolumn{3}{|c|}{ Putative target transcripts of miRNAs upregulated in CPT2-deficient fibroblasts: } \\
\hline SIRT1 & SIRT1 & $2 \times 449 b / 539 / 9 / 651 /$ \\
\hline STK11 & LKB1 & $483 /$ \\
\hline PRKAA1 & AMPK subunit & $301 / 449 b / 539 / 371 / 9 / 651 /$ \\
\hline PRKAA2 & AMPK subunit & $483 / 301 / 2 \times 449 b / 206 / 4 \times 371 / 3 \times 10 b / 3 \times 651 /$ \\
\hline PRKAB1 & AMPK subunit & $483 / 301 / 9 /$ \\
\hline PPARGC1A & PGC-1 $\alpha$ & $2 \times 301 / 539 / 196 a-2 /$ \\
\hline ALDH7A1 & PDE & $2 \times 483 / 449 b / 2 \times 3712 \times 10 b / 651 /$ \\
\hline ESR1 & ER & $483 / 3 \times 301 / 2 \times 206 / 371 / 2 \times 9 / 196 a-2 /$ \\
\hline ESRRA & ERR $\alpha$ & $449 \mathrm{~b} /$ \\
\hline NRF1 & NRF1 & $483 / 449 b / 2 \times 539 / 3 \times 371 / 9 /$ \\
\hline NFE2L2 & NRF2 & $651 /$ \\
\hline TFAM & TFAM & $483 / 206 / 539 / 2 \times 371 / 10 b / 9 / 651 /$ \\
\hline \multicolumn{3}{|c|}{ Putative target transcripts of miRNAs downregulated in CPT2-deficient fibroblasts: } \\
\hline SIRT1 & SIRT1 & 211/141/136/181a2,c/496/126-5p/ \\
\hline STK11 & LKB1 & - \\
\hline PRKAA1 & AMPK subunit & $496 / 126-5 p / 144 /$ \\
\hline PRKAA2 & AMPK subunit & let-7a3,d,g/2 × 141/203/3 × 181a2,c/4 × 126-5p/144/9/ \\
\hline PRKAB1 & AMPK subunit & $2 \times 141 / 2 \times 203 / 181 \mathrm{a} 2, \mathrm{c} /$ \\
\hline PPARGC1A & PGC-1 $\alpha$ & let-7a3,d,g/211/141/136/203/496/3 × 126-5p/144/ \\
\hline ALDH7A1 & PDE & $141 / 2 \times 136 / 203 /$ \\
\hline ESR1 & ER & 211/136/203/181a2,c/496/ \\
\hline ESRRA & ERR $\alpha$ & - \\
\hline NRF1 & NRF1 & $2 \times 211 / 181 \mathrm{a} 2, \mathrm{c} /$ \\
\hline NFE2L2 & NRF2 & $181 \mathrm{a} 2, \mathrm{c} / 496 /$ \\
\hline TFAM & TFAM & $211 / 4 \times 141 / 2 \times 136 / 2 \times 203 / 181 \mathrm{a} 2, \mathrm{c} / 496 / 4 \times 126-5 \mathrm{p} / 4 \times 144 /$ \\
\hline \multicolumn{3}{|c|}{ Putative target transcripts of miRNAs upregulated after RSV treatment of CPT2-deficient fibroblasts: } \\
\hline SIRT1 & SIRT1 & 199a1-5p/ \\
\hline STK11 & LKB1 & $199 a 1-5 p /$ \\
\hline PRKAA1 & AMPK subunit & - \\
\hline PRKAA2 & AMPK subunit & $219 / 2 \times 299 / 193 a / 199 a 1-5 p / 2 \times 337 /$ \\
\hline PRKAB1 & AMPK subunit & 193a/ \\
\hline PPARGC1A & PGC-1 $\alpha$ & $219 / 193 a / 2 \times 199 a 1-5 p /$ \\
\hline ALDH7A1 & PDE & $199 \mathrm{a} 1-5 \mathrm{p} / 2 \times 337 /$ \\
\hline ESR1 & ER & $219 / 299 / 2 \times 193 a / 337 /$ \\
\hline ESRRA & ERR $\alpha$ & - \\
\hline NRF1 & NRF1 & $199 a 1-5 p /$ \\
\hline NFE2L2 & NRF2 & $337 /$ \\
\hline TFAM & TFAM & $299-5 p / 2 \times 193 a / 199 a 1-5 p / 2 \times 337 /$ \\
\hline \multicolumn{3}{|c|}{ Putative target transcripts of miRNAs downregulated after RSV treatment of CPT2-deficient fibroblasts: } \\
\hline SIRT1 & SIRT1 & $181 \mathrm{~d} / 23 \mathrm{a} /$ \\
\hline STK11 & LKB1 & $20 b / 17-5 p /$ \\
\hline PRKAA1 & AMPK subunit & $2 \times 101-1 / 2 / 16-1 / 21 / 26 a /$ \\
\hline PRKAA2 & AMPK subunit & $3 \times 181 \mathrm{~d} / 21 / 20 \mathrm{~b} /$ let-7c,d $/ 17-5 / 2 \times 146 \mathrm{a} / 376 \mathrm{~b} / 26 \mathrm{a} / 23 \mathrm{a} /$ \\
\hline PRKAB1 & AMPK subunit & 181d/146a/ \\
\hline PPARGC1A & PGC- $1 \alpha$ & $101-1 / 2 /$ let-7d $/ 376 b / 26 a / 2 \times 23 a /$ \\
\hline ALDH7A1 & PDE & $16-1 / 2 \times 20 b / 2 \times 17-5 p / 146 a /$ \\
\hline ESR1 & ER & $181 d / 21 / 3 \times 20 b / 3 \times 17-5 p / 146 a / 2 \times 26 a / 2 \times 103-1 / 23 a /$ \\
\hline ESRRA & $\mathrm{ERR} \alpha$ & $16-1 / 103-1 / 423 /$ \\
\hline NRF1 & NRF1 & $181 \mathrm{~d} / 2 \times 21 /$ \\
\hline NFE2L2 & NRF2 & $181 d / 103-1 /$ \\
\hline TFAM & TFAM & $181 d / 3 \times 20 b / 3 \times 17-5 p / 2 \times 376 b / 26 a / 23 a /$ \\
\hline
\end{tabular}

* MiRNAs are given in the same order as in Tables 1 and 2. The sign " $x$ " indicates the number of putative target sequence for a given miRNA. Target transcripts were identified using the Targetscan software (www.targetscan.com). Numbers in front of miRNAs indicate that more than one consensus target site for this miRNA is present in the $3^{\prime}$-untranslated region of the transcript. For instance, SIRT1 3-untranslated region contains two consensus target sequences for $m i R-449 b$.

Consensus target sites in the $3^{\prime}$-untranslated regions of the same genes for miRNAs that were upregulated or downregulated following RSV treatment of CPT2-deficient fibroblasts (Table 2) show a similar distribution. While seven of the above genes are potential targets of miR-199a1-5p and 5 are potential targets of miR-337 (both upregulated following RSV treatment). Table 3 also shows that seven genes of the above pathways are also putative targets of $m i R-181 d$, and five of them are 
also targets of $m i R-20 b, m i R-17-5 p, m i R-26 a$, and $m i R-23 a$ (all of these miRNAs being downregulated following RSV treatment). Given that the $3^{\prime}$-untranslated regions of several of these genes contains more than one consensus target site for $m i R-20 b, m i R-17-5 p$, or other miRNAs, it is likely that RSV may change the expression of genes that encode factors implicated in these two pathways, and therefore fatty acid oxidation, through both miRNA-dependent and miRNA-independent mechanisms. Finally, as miRNAs that changed following RSV treatment of control fibroblasts are fairly different from those that changed following RSV treatment of CPT2-deficient fibroblasts (Table 2), it is possible that RSV effects on miRNA expression might depend on other factors-factors most likely implicated in modulating the activity of fatty acid oxidation in mitochondria.

In conclusion, this paper is the first to report changes in microRNA expression associated with CPT2-deficiency in human fibroblasts and sheds some new light on potential beneficial effects of RSV through modifying miRNA expression. In particular, it appears likely that changes in miRNA levels in CPT2-deficient cells might, at least in part, be involved in abnormal fatty acid oxidation. The emerging role of microRNAs in lipid metabolism has been emphasized in recent reviews [32] reporting that miRNAs are critical regulators of lipid synthesis, fatty acid B-oxidation, and lipoprotein metabolism. Changes in the expression of crucial miRNAs can impact gene regulatory network, driving to metabolic syndrome and its related pathologies. This review introduced epigenetic and transcriptional regulation of miRNA expression, especially miR-378 (controlling FABP7, IGFBP3, PDCD4, and PPAR- $\alpha$ mRNA expression) and $m i R-21$ (controlling $C R A T, M E D 13, E R R \gamma, G A B P 1$, and IGF1 $\alpha$ mRNA expression). In this paper, we found that $m i R-378$ was downregulated by RSV in control fibroblasts and that $m i R-21$ was downregulated by RSV in CPT2-deficient fibroblasts. In addition, miR-21 could putatively target NRF1 mRNAs, which encode a transcription factor implicated in respiratory control (Table 3).

Further studies will be required to assess the impact of these changes in miRNA expression on RSV-induced stimulation of mitochondrial fatty acid oxidation in CPT2-deficient cells and to identify factors that mediate these RSV effects.

\section{Materials and Methods}

\subsection{Primary Human Fibroblasts and Cell Treatments}

CPT2-deficient and control human skin fibroblasts used in this study have been described previously [5]. Point mutations and genotypes of the cells are the following: nucleotides changes, c.338C > T and c.371G > A, and consequently amino acid changes, S113L and R124Q. For cell treatment, a medium of Ham's F10 media containing glutamine, 12\% fetal bovine serum, $100 \mathrm{U} / \mathrm{mL}$ penicillin, and $0.1 \mathrm{mg} / \mathrm{mL}$ streptomycin was removed and replaced with fresh medium containing either the vehicle, DMSO $0.1 \%$, or $75 \mu \mathrm{M}$ resveratrol (RSV). Cells were subsequently cultivated for $72 \mathrm{~h}$ before RNA extraction.

\subsection{RNA Extraction, Purification, and Micro RNAs Screening and Analysis}

RNAs extracted with TRIzol (Invitrogen) were subsequently subjected to DNase digestion (Turbo-DNase-Ambion), as previously described [2]. MiRNA microarrays were analyzed as previously described [2]. Four independent repeats (i.e., cell cultures) were used for each group.

\subsection{RNA Labeling and Micro-Arrays}

Five micrograms of total RNA were labeled by reverse transcription at $37{ }^{\circ} \mathrm{C}$ for $90 \mathrm{~min}$ using a biotin-labeled rand-octomer oligo primer. An RT reaction mix was further denatured in $0.5 \mathrm{~N} \mathrm{NaOH} / 1 \mathrm{mM}$ EDTA at $65{ }^{\circ} \mathrm{C}$ for $15 \mathrm{~min}$ and neutralized by $1 \mathrm{M}$ Tris $\mathrm{HCl} \mathrm{pH}$ 7.6. Biotin signal was detected with an Alexa 647-Streptavidin conjugate. Chips were hybridized on Tecan HS 4800 hybridization station. Chips were pre-hybridized at $25{ }^{\circ} \mathrm{C}$ for $30 \mathrm{~min}$ in the buffer: $6 \times \mathrm{SSPE} / 30 \%$ formamide/ $\times$ Denhardt's solution. Chips were further hybridized with a labeled target in $6 \times \mathrm{SSPE} / 30 \%$ formamide at $25^{\circ} \mathrm{C}$ for $18 \mathrm{~h}$. Hybridization and post-hybridization washing 
was conducted in $0.75 \times \mathrm{TNT}$ (Tris, sodium, Tween 20 ) at $37^{\circ} \mathrm{C}$ for $40 \mathrm{~min}$. The chips were stained by streptavidin-alexa647 (1:500) dilution in TNT for $30 \mathrm{~min}$. Post-staining washing was conducted in $1 \times$ TNT FOR $40 \mathrm{~min}$.

\section{Conclusions}

Taking account that RSV enhances residual CPT2 activities in human fibroblasts derived from CPT2-deficient patients and restores normal fatty acid oxidation rates, we now report changes in miRNA expression linked to CPT2-deficiency, and we identify miRNAs whose expression changed following RSV treatment of control or CPT2-deficient fibroblasts isolated from patients. Our findings suggest that RSV consumption might exert beneficiary effects in patients with CPT2-deficiency through miRNAs expression modulation.

Acknowledgments: This work was supported by ANR (grant ANR-09-GENO-024-01). We thank Jean-Jacques Michaille from Université de Bourgogne-Franche Comté, Laboratoire Bio-PeroxIL, Dijon, France, for his review and advice.

Author Contributions: N.L. and D.D. conceived and designed the experiments; V.A. performed the experiments; V.A., D.D., M.C.-M., and N.L. analyzed the data; V.A., F.D., and J.B. contributed reagents/materials/analysis tools; N.L. wrote the paper.

Conflicts of Interest: The authors declare no conflict of interest.

\section{References}

1. Latruffe, N.; Rifler, J.-P. Bioactive polyphenols from grape and wine. Curr. Pharm. Des. 2013, 19, $6053-6063$. [CrossRef] [PubMed]

2. Jeandet, P.; Delaunois, B.; Conreux, A.; Donnez, D.; Nuzzo, V.; Cordelier, S.; Clément, C.; Courot, E. Biosynthesis, metabolism, molecular engineering, and biological functions of stilbene phytoalexins in plants. BioFactors 2010, 36, 331-341. [CrossRef] [PubMed]

3. Jeandet, P.; Hébrard, C.; Deville, M.A.; Cordelier, S.; Dorey, S.; Aziz, A.; Crouzet, J. Deciphering the role of phytoalexins in plant-microorganism interactions and human health. Molecules 2014, 19, 18033-18056. [CrossRef] [PubMed]

4. Tili, E.; Michaille, J.J.; Adair, B.; Alder, H.; Limagne, E.; Taccioli, C.; Ferracin, M.; Delmas, D.; Latruffe, N.; Croce, C.M. Resveratrol decreases the levels of miR-155 by upregulating miR-663, a microRNA targeting JunB and JunD. Carcinogenesis 2010, 31, 1561-1566. [CrossRef] [PubMed]

5. Limagne, E.; Lançon, A.; Delmas, D.; Cherkaoui-Malki, M.; Latruffe, N. Resveratrol Interferes with IL1- $\beta$-Induced Pro-Inflammatory Paracrine Interaction between Primary Chondrocytes and Macrophages. Nutrients 2016, 8, 280. [CrossRef] [PubMed]

6. Lin, H.Y.; Delmas, D.; Vang, O.; Hsieh, T.C.; Lin, S.; Cheng, G.Y.; Chiang, H.L.; Chen, C.E.; Tang, H.Y.; Crawford, D.R.; et al. Mechanisms of ceramide-induced COX-2-dependent apoptosis in human ovarian cancer OVCAR-3 cells partially overlapped with resveratrol. J. Cell. Biochem. 2013, 114, 1940-1954. [CrossRef] [PubMed]

7. Bastin, J.; Lopes-Costa, A.; Djouadi, F. Exposure to resveratrol triggers pharmacological correction of fatty acid utilization in human fatty acid oxidation-deficient fibroblasts. Hum. Mol. Genet. 2011, 20, $2048-2057$. [CrossRef] [PubMed]

8. Karius, T.; Schnekenburger, M.; Dicato, M. MicroRNAs in cancer management and their modulation by dietary agents. Biochem. Pharmacol. 2012, 83, 1591-1601. [CrossRef] [PubMed]

9. Li, Y.; Kong, D.; Wang, Z.; Sarkar, F.H. Regulation of microRNAs by natural agents: An emerging field in chemoprevention and chemotherapy research. Pharm. Res. 2010, 27, 1027-1041. [CrossRef] [PubMed]

10. Milenkovic, D.; Jude, B.; Morand, C. MiRNA as molecular target of polyphenols underlying their biological effects. Free Radic. Biol. Med. 2013, 64, 40-51. [CrossRef] [PubMed]

11. Lançon, A.; Kaminski, J.; Tili, E.; Michaille, J.J.; Latruffe, N. Control of MicroRNA expression as a new way for resveratrol to deliver its beneficial effects. J. Agric. Food Chem. 2012, 60, 8783-8789. [CrossRef] [PubMed]

12. Lançon, A.; Michaille, J.J.; Latruffe, N. Effects of dietary phytophenols on the expression of microRNAs involved in mammalian cell homeostasis. J. Sci. Food Agric. 2013, 93, 3155-3164. [CrossRef] [PubMed] 
13. Latruffe, N.; Lançon, A.; Frazzi, R.; Aires, V.; Delmas, D.; Michaille, J.J.; Djouadi, F.; Bastin, J.; Cherkaoui, J.; Malki, M. Exploring new ways of regulation by resveratrol involving miRNAs, with emphasis on inflammation. Ann. N. Y. Acad. Sci. 2015, 1348, 97-106. [CrossRef] [PubMed]

14. Tili, E.; Michaille, J.J.; Alder, H.; Volinia, S.; Delmas, D.; Latruffe, N.; Croce, C.M. Resveratrol modulates the levels of microRNAs targeting genes encoding tumor-suppressors and effectors of TGF $\beta$ signaling pathway in SW480 cells. Biochem. Pharmacol. 2010, 80, 2057-2065. [CrossRef] [PubMed]

15. Kumar, A.; Rimando, A.M.; Levenson, A.S. Resveratrol and pterostilbene as a microRNA-mediated chemopreventive and therapeutic strategy in prostate cancer. Ann. N. Y. Acad. Sci. 2017. [CrossRef] [PubMed]

16. Wu, F.; Cui, L. Resveratrol suppresses melanoma by inhibiting NF-kB/miR-221 and inducing TFG expression. Arch. Dermatol. Res. 2017. [CrossRef] [PubMed]

17. Venkatadri, R.; Muni, T.; Iyer, A.K.; Yakisich, J.S.; Azad, N. Role of apoptosis-related miRNAs in resveratrol-induced breast cancer cell death. Cell Death Dis. 2016, 7, e2104. [CrossRef] [PubMed]

18. Bai, T.; Dong, D.S.; Pei, L. Synergistic antitumor activity of resveratrol and miR-200c in human lung cancer. Oncol. Rep. 2014, 31, 2293-2297. [CrossRef] [PubMed]

19. Gracia, A.; Miranda, J.; Fernández-Quintela, A.; Eseberri, I.; Garcia-Lacarte, M.; Milagro, F.I.; Martínez, J.A.; Aguirre, L.; Portillo, M.P. Involvement of miR-539-5p in the inhibition of de novo lipogenesis induced by resveratrol in white adipose tissue. Food Funct. 2016, 7, 1680-1688. [CrossRef] [PubMed]

20. Gracia, A.; Fernández-Quintela, A.; Miranda, J.; Eseberri, I.; González, M.; Portillo, M.P. Are miRNA-103, miRNA-107 and miRNA-122 Involved in the Prevention of Liver Steatosis Induced by Resveratrol? Nutrients 2017, 9, 360. [CrossRef] [PubMed]

21. Ma, C.; Wang, Y.; Shen, A.; Cai, W. Resveratrol upregulates SOCS1 production by lipopolysaccharide-stimulated RAW264.7 macrophages by inhibiting miR-155. Int. J. Mol. Med. 2017, 39, 231-237. [CrossRef] [PubMed]

22. Tili, E.; Michaille, J.J. Promiscuous Effects of Some Phenolic Natural Products on Inflammation at Least in Part Arise from Their Ability to Modulate the Expression of Global Regulators, Namely microRNAs. Molecules 2016, 21, 1263. [CrossRef] [PubMed]

23. Wang, Z.H.; Zhang, J.L.; Duan, Y.L.; Zhang, Q.S.; Li, G.F.; Zheng, D.L. MicroRNA-214 participates in the neuroprotective effect of Resveratrol via inhibiting $\alpha$-synuclein expression in MPTP-induced Parkinson's disease mouse. Biomed. Pharmacother. 2015, 74, 252-256. [CrossRef] [PubMed]

24. Guo, D.W.; Han, Y.X.; Cong, L.; Liang, D.; Tu, G.J. Resveratrol prevents osteoporosis in ovariectomized rats by regulating microRNA-338-3p. Mol. Med. Rep. 2015, 12, 2098-2106. [CrossRef] [PubMed]

25. Aires, V.; Delmas, D.; Le Bachelier, C.; Latruffe, N.; Schlemmer, D.; Benoit, J.F.; Djouadi, F.; Bastin, J. Stilbenes and resveratrol metabolites improve mitochondrial fatty acid oxidation defects in human fibroblasts. Orphanet J. Rare Dis. 2014, 9, 79. [CrossRef] [PubMed]

26. Lopes Costa, A.; Le Bachelier, C.; Mathieu, L.; Rotig, A.; Boneh, A.; De Lonlay, P.; Tarnopolsky, M.A.; Thorburn, D.R.; Bastin, J.; Djouadi, F. Beneficial effects of resveratrol on respiratory chain defects in patients' fibroblasts involve estrogen receptor and estrogen-related receptor alpha signaling. Hum. Mol. Genet. 2014, 23, 2106-2119. [CrossRef] [PubMed]

27. Mathieu, L.; Costa, A.L.; Le Bachelier, C.; Slama, A.; Lebre, A.S.; Taylor, R.W.; Bastin, J.; Djouadi, F. Resveratrol attenuates oxidative stress in mitochondrial Complex I deficiency: Involvement of SIRT3. Free Radical Biol. Med. 2016, 96, 190-198. [CrossRef] [PubMed]

28. Brenmoehl, J.; Hoeflich, A. Dual control of mitochondrial biogenesis by sirtuin 1 and sirtuin 3. Mitochondrion 2013, 13, 755-761. [CrossRef] [PubMed]

29. Rodriguez-Ramiro, I.; Vauzour, D.; Minihane, A.M. Polyphenols and non-alcoholic fatty liver disease: Impact and mechanisms. Proc. Nutr. Soc. 2016, 75, 47-60. [CrossRef] [PubMed]

30. Price, N.L.; Gomes, A.P.; Ling, A.J.; Duarte, F.V.; Martin-Montalvo, A.; North, B.J.; Agarwal, B.; Ye, L.; Ramadori, G.; Teodoro, J.S.; et al. SIRT1 is required for AMPK activation and the beneficial effects of resveratrol on mitochondrial function. Cell Metab. 2012, 15, 675-690. [CrossRef] [PubMed] 
31. Bastin, J.; Djouadi, F. Resveratrol and Myopathy. Nutrients 2016, 8, 254. [CrossRef] [PubMed]

32. Yanga, Z.; Cappelloa, T.; Wang, L. Emerging role of microRNAs in lipid metabolism. Acta Pharm. Sin. B 2015, 5, 145-150. [CrossRef] [PubMed]

Sample Availability: Resveratrol commercially available.

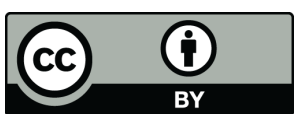

(C) 2017 by the authors. Licensee MDPI, Basel, Switzerland. This article is an open access article distributed under the terms and conditions of the Creative Commons Attribution (CC BY) license (http:/ / creativecommons.org/licenses/by/4.0/). 